Génét. Sél. Evol., 1985, 17 (4), 419-434

\title{
Deux cas de freemartinisme chez des moutons Romanov (Ovis aries)
}

\author{
Michèle MATEJKA *, E.P. CRIBIU *, S. CHAFFAUX **, \\ O. SCHMITT *** et G. RICORDEAU ****
}

*I.N.R.A., Laboratoire de Cytogénétique, Centre de Recherches Zootechniques F 78350 Jouy-en-Josas

** Ecole Nationale Vétérinaire d'Alfort, Pathologie de la Reproduction F 94704 Maisons-Alfort Cedex

***I.N.R.A., Laboratoire de Recherches sur la Viande, Centre de Recherches Zootechniques, F 78350 Jouy-en-Josas

**** I.N.R.A., Station d'Amélioration génétique des Animaux

Centre de Recherches de Toulouse, B.P. 27, Auzeville, F 31326 Castanet-Tolosan Cedex

\section{Résumé}

Deux cas de freemartinisme chez des brebis Romanov sont décrits. Malgré des organes génitaux externes normaux, les appareils reproducteurs internes sont fortement masculinisés avec des testicules, des épididymes et des canaux déférents. Aucune trace de dérivés des canaux de Müller n'a été observée. Toutes deux possèdent un chimérisme chromosomique $\mathrm{XX} / \mathrm{XY}$ au niveau des cellules hématopoḯtiques du sang et de la moelle, mais pas au niveau des cellules rénales. Enfin, le phénomène de freemartinisme chez le mouton est discuté à la lumière de ces résultats et des travaux antérieurs.

Mots clés : Mouton, Romanov, intersexualité, freemartinisme, chromosomes sexuels, anomalies chromosomiques.

\section{Summary}

Two cases of freemartinism in Romanov sheep

Two cases of freemartinism in Romanov ewes are described. Although their external genitalia were normal, their internal reproductive tracts were strongly differentiated towards the male form with testes, epididymes and vasa deferentia. No traces of Müller derivatives were present. The two ewes carry an $\mathrm{XX} / \mathrm{XY}$ chimerism in blood and bone marrow hematopoietic cells but not in kidney cells. The phenomenon of freemartinism in sheep is discussed.

Key words : Sheep, Romanov, intersexuality, freemartinism, sex chromosomes, chromosomal abnormalities. 


\section{Introduction}

Le freemartinisme qui est un phénomène bien connu des éleveurs de bétail depuis la plus haute antiquité est causé par l'installation d'anastomoses vasculaires placentaires précoces entre 2 fœutus de sexes différents (KELLER \& TANDLER, 1916; LILlie, 1917). Chez les bovins 90 p. 100 des co-jumelles de mâles sont des intersexuées, possédant non seulement des gonades et des conduits génitaux diversement masculinisés (LILLIE, 1917), mais aussi un chimérisme érythrocytaire (OWEN, 1945) et leucocytaire (OHNO et al., 1962).

Chez le Mouton, les freemartins sont beaucoup plus rares que chez le Bœuf domestique puisque les anastomoses vasculaires ne s'installent que dans 0,8 à 10 p. 100 des cas de gestations gemellaires (StORMONT et al., 1953 ; Alexander \& Williams, 1964 ; DaIN, 1971).

Cependant, même s'ils sont peu nombreux, des cas d'infertilité s'observent de plus en plus régulièrement dans les souches prolifiques. OWEN (1980) les remarque dans des portées de 3 agneaux et plus dans la souche prolifique Cambridge. HaNRAHAN (1984) signale des tractus anormaux chez ses brebis Finnoises dont la prolificité moyenne est de l'ordre de 3 agneaux par mise bas. Dans les troupeaux I.N.R.A. de race Romanov dont la prolificité est de 2,8 à 3,3 suivant la saison, on observe également 2 à 3 p. 100 d'agnelles infertiles, mais ce pourcentage est certainement sous-estimé car les agnelles légèrement masculinisées (notamment au niveau de la vulve) sont éliminées avant la mise à la reproduction et ne sont pas comptabilisées parmi les animaux stériles.

Cette note a pour but de présenter 2 cas de freemartinisme chez des moutons Romanov. et comprend l'étude du caryotype de plusieurs tissus ainsi que la description des organes génitaux.

\section{Matériel et méthodes}

\section{A. Animaux}

Les 2 brebis Romanov sont issues du troupeau I.N.R.A. du Domaine de Langlade (près de Toulouse) consacré à l'étude génétique des composantes de la taille de portée (Ricordeau et al., 1982).

Elles sont nées en janvier 1983 de mères fécondées sur œstrus naturel, par 2 pères différents. Elles appartiennent respectivement à des portées de 5 et 4 agneaux des 2 sexes, tous vivants. La portée de naissance de la brebis 1 est composée de 2 mâles et 3 femelles dont les poids de naissance, en $\mathrm{kg}$, sont respectivement : $1,2$ ( $\hat{o}) ; 1,5(\hat{o}) ; 1,5(q) ; 1,5(q) ; 1,1$ (brebis 1). Parmi les 2 femelles pesant $1,5 \mathrm{~kg}$, l'une est fertile et l'autre n'a pas été retenue pour la reproduction. La portée de naissance de la brebis 2 comprend 1 mâle et 3 femelles ayant des poids de naissance exprimés en $\mathrm{kg}$ de : 2,0 (令);2,4 (q);2,3 (q) : 2,0 (brebis 2). La femelle pesant $2,4 \mathrm{~kg}$ est fertile et l'autre a été éliminée de la reproduction.

Les 2 brebis étudiées étaient âgées de 16 mois au moment de l'abattage. 


\section{B. Cytogénétique}

Le caryotype des 2 animaux a été établi à partir de cultures de sang périphérique, de moelle osseuse et de reins. Après avoir été prélevé à la veine jugulaire, $0,5 \mathrm{ml}$ de sang entier hépariné a été versé dans un tube de culture contenant : $9 \mathrm{ml}$ de mélange nutritif HAM'S F 12, 20 p. 100 de sérum fæatal bovin, $100 \mathrm{UI} / \mathrm{ml}$ de pénicilline, $100 \mathrm{~kg} / \mathrm{ml}$ de streptomycine et $25 \mathrm{~kg} / \mathrm{ml}$ de concanavaline. Après 3 jours d'incubation à $37^{\circ} \mathrm{C}$, un blocage de 1 h $30 \mathrm{~min}$ à la colcémide (concentration finale : $0,03 \mathrm{lg} / \mathrm{ml})$, un choc hypotonique dans du citrate de sodium $(0,85$ p. 100) pendant 20 min à $37^{\circ} \mathrm{C}$ et 3 fixations de $1 \mathrm{~h}$, les suspensions cellulaires ont été étalées sur lame. Les préparations ont ensuite été séchées à la flamme, puis colorées avec du Giemsa 4 p. 100.

La moelle osseuse a été prélevée avec une seringue dans une des côtes de chaque animal. Chaque tube de culture contenant le même milieu que pour les lymphocytes a été ensemencé avec $0,1 \mathrm{ml}$ de ce prélèvement puis mis à incuber pendant $24 \mathrm{~h}$ à $37^{\circ} \mathrm{C}$. Les cellules ont ensuite été traitées, selon la technique décrite pour les lymphocytes.

Pour les reins, l'analyse chromosomique a été effectuée sur des cultures cellulaires dont la durée variait entre 3 et 15 jours. Les cellules, obtenues à partir de petits fragments de reins dilacérés et digérés dans une solution de trypsine à $2,5 \mathrm{~g} / 1$, ont été cultivées en couche monocellulaire dans des tubes Falcon de $75 \mathrm{~cm}^{2}$ de surface contenant du milieu RPMI 1640 supplémenté avec 10 p. 100 de sérum bovin fœtal, $100 \mathrm{UI} / \mathrm{ml}$ de pénicilline et $100, \mathrm{~g} / \mathrm{ml}$ de streptomycine. Les premiers repiquages ont été réalisés dès le troisième jour quand la couche cellulaire envahissait entièrement la surface interne des flacons plats. Après avoir décollé les cellules à l'aide d'une solution de trypsine et ajouté $10 \mathrm{ml}$ de milieu dans chaque flacon, la suspension ainsi obtenue a été répartie dans 2 ou 3 nouveaux flacons. Les seconds repiquages ont ensuite eu lieu une dizaine de jours plus tard. A l'occasion de ces 2 passages, une petite quantité de la suspension cellulaire a été distribuée dans des tubes à lamelles de type Leighton à raison de $0,5 \mathrm{ml}$ par tube. Après 24 à 48 heures d'incubation à $37^{\circ} \mathrm{C}$ et un blocage de 1 h $30 \mathrm{~min}$ à la colcémide (concentration finale $0,03 \mu \mathrm{g} / \mathrm{ml}$ ), les métaphases ont été traitées selon la méthode de DE Grouchy \& Roubin (1965) et colorées avec une solution de Giemsa à 4 p. 100.

\section{Histologie}

Les gonades ont été fixées dans le liquide de Bouin et les coupes colorées avec de l'Hemalun-éosine.

\section{Résultats}

\section{A. Description morphologique}

Les organes génitaux externes sont normaux et de sexe femelle. La vulve et le clitoris sont normalement développés. L'examen post-mortem laisse apparaître un tractus génital mâle sans formations femelles apparentes : pas d'utérus, pas d'oviducte. 


\section{Brebis 1}

La distance ano-génitale est celle d'une femelle normale $(1,5 \mathrm{~cm})$. Le vestibule qui a des dimensions identiques à celles d'une brebis de cet âge $(4 \mathrm{~cm})$, se termine en un cul-de-sac. Les canaux déférents avec des ampoules normales, sont présents mais les vésicules séminales sont absentes. Des 2 côtés, les gonades de $0,7 \mathrm{~cm}$ de diamètre sont situées entre l'anneau inguinal profond et l'anneau inguinal superficiel. De ce fait elles ne sont ni totalement externes, ni entièrement abdominales puisqu'engagées dans le trajet inguinal. Elles sont coiffées d'un complexe pampiniforme développé et enveloppées d'une vaginale présentant un crémaster. Sur la figure 1, la vaginale de droite est ouverte. Des deux côtés un épididyme bien développé, avec tête, corps et queue est présent.

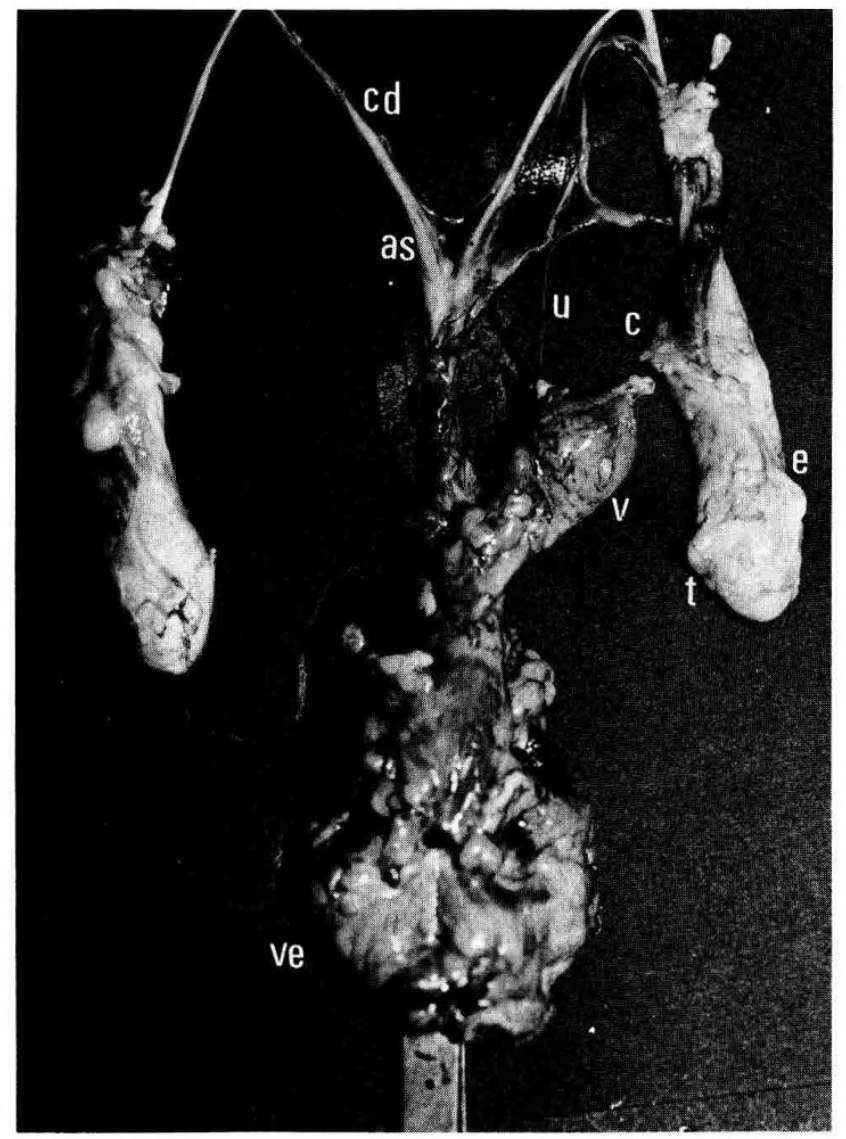

FIG. 1

Appareil génital interne de l'animal 1.

Internal genitalia of animal $n^{\circ} 1$.

$\mathrm{t}$ : testicule (testis); e : épididyme (epididymis); c : crémaster (cremaster); cd : canal déférent (ductus deferens); as : ampoule séminale (ampullae); u : uretère (ureter) ; v : vessie (bladder); ve : vestibule (vestibule). 


\section{Brebis 2}

La distance ano-génitale $(1,5 \mathrm{~cm})$ et le vestibule $(4 \mathrm{~cm})$ ont les mêmes dimensions que pour la brebis 1 . Le méat urinaire se trouve situé en arrière du cul-de-sac du vestibule, à $1 \mathrm{~cm}$ de celui-ci. Les 2 gonades, plus petites et plus sphériques que pour la brebis 1, sont abdominales. Elles n'ont pas migré. Les crémasters sont moins développés que chez la brebis 1 et les canaux déférents sont aussi moins longs. Le complexe pampiniforme existe des 2 cotés. A droite l'épididyme est complet avec tête, corps et queue tandis qu'à gauche seule la tête de l'épipidyme est présente (fig. 2).

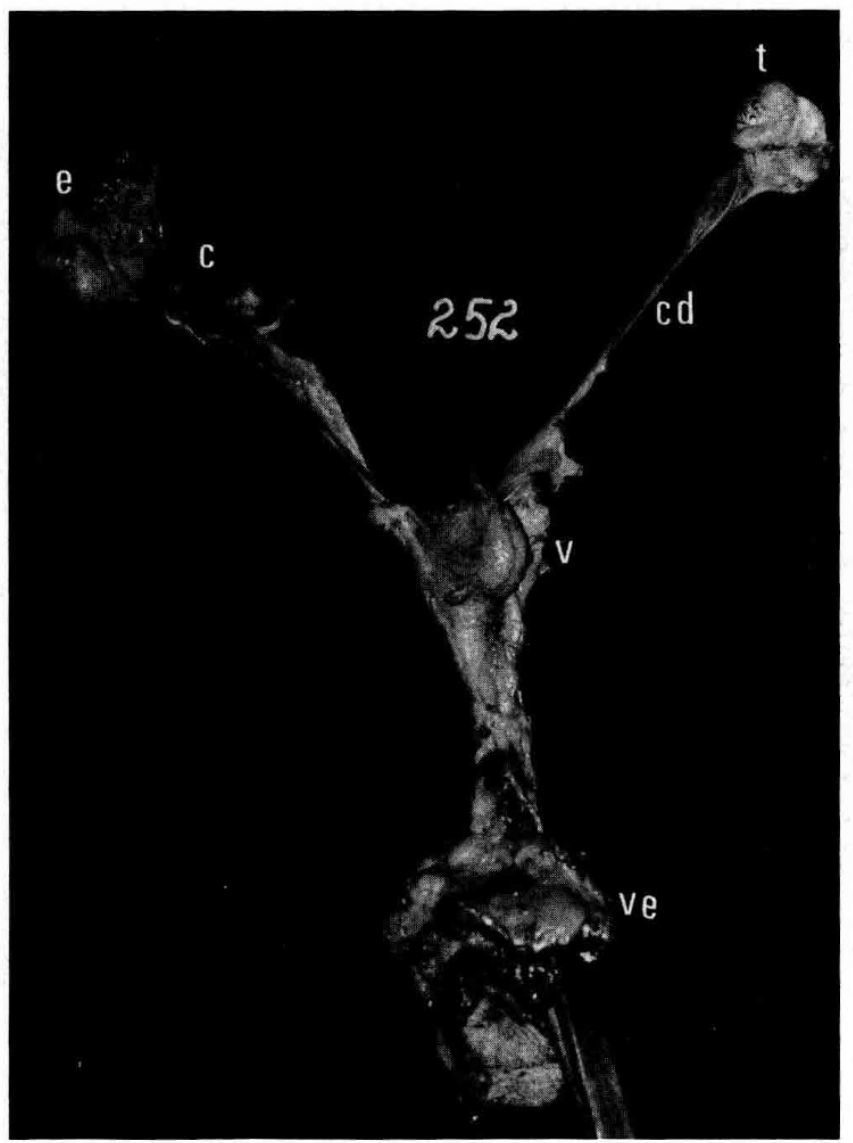

FIG. 2

Appareil génital interne de l'animal 2.

Internal genitalia of animal $n^{\circ} 2$.

$\mathrm{t}$ : testicule (testis); e : épididyme (epididymis); c : crémaster (cremaster) ; cd : canal déférent (ductus deferens); $v$ : vessie (bladder); ve : vestibule (vestibule). 


\section{B. Histologie}

L'épididyme, les canaux déférents des 2 animaux ont une structure histologique identique à celle des mâles normaux du même âge mais aucun gamète n'est présent dans la lumière des canaux. Seule une proportion anormalement importante de tissu conjonctif péritubaire est notée chez la brebis 2 .

Pour les 2 animaux les tubes séminifères sont constitués de cellules somatiques organisées en cordons, sans lumière, ne contenant pas de cellules germinales. Les cordons sont entourés d'une couche péritubulaire comprenant une membrane basale et des cellules fibroblastiques. Cette couche est épaisse. Cette structure est peu perturbée dans les 2 gonades de la brebis 2. Par contre chez la brebis 1, par endroits la couche péritubulaire est plissée, comme dans le cas de Sertolinome (PICON et al., 1978, Scheib-Gluntz, 1984). Pour les 2 animaux seules quelques rares cellules de Leydig ont été observées. Aucune structure femelle n'a été mise en évidence (fig. 3 et 4).

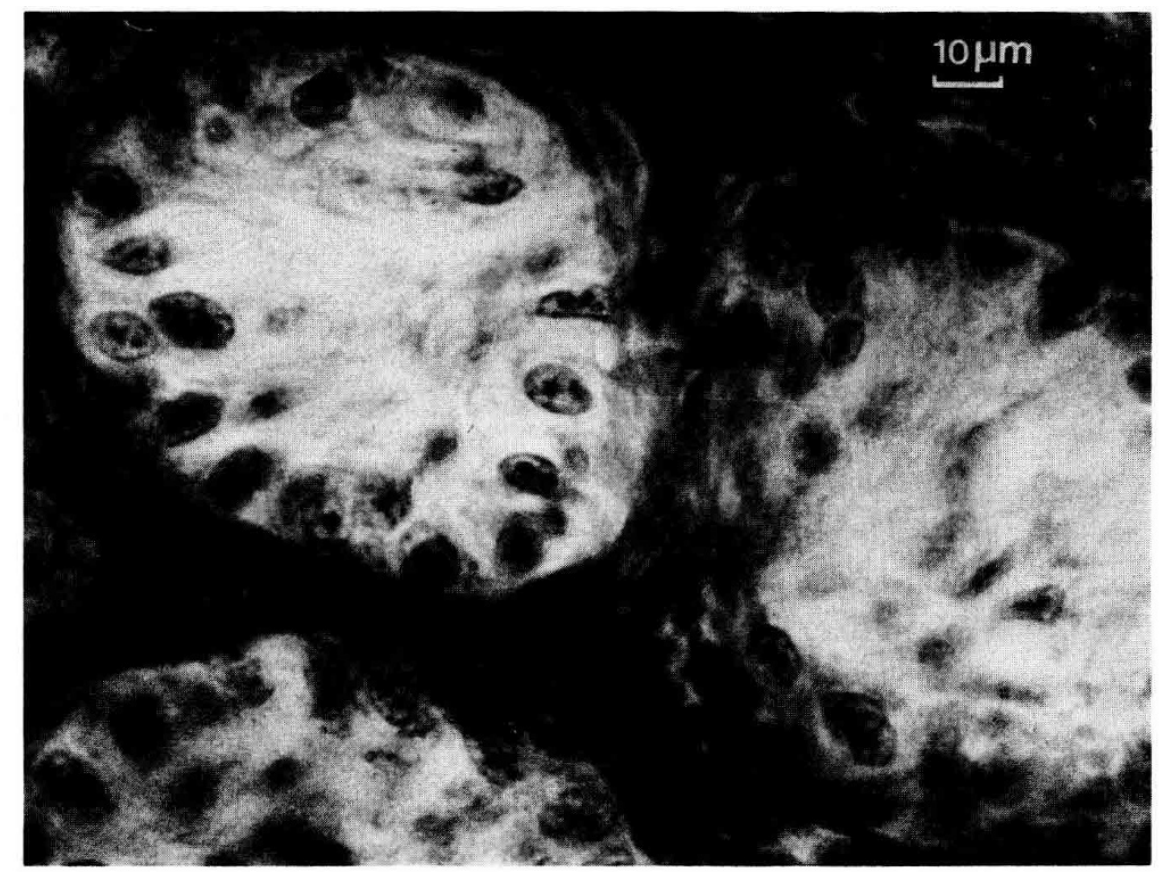

FIG. 3.

Coupe de testicule (animal 2).

Section of testis (animal $n^{\circ} 2$ ).

\section{Cytogénétique}

Les caryotypes des 2 brebis effectués à partir des métaphases des cellules rénales sont ceux de femelles normales et sont composés chacun de 54 chromo- 


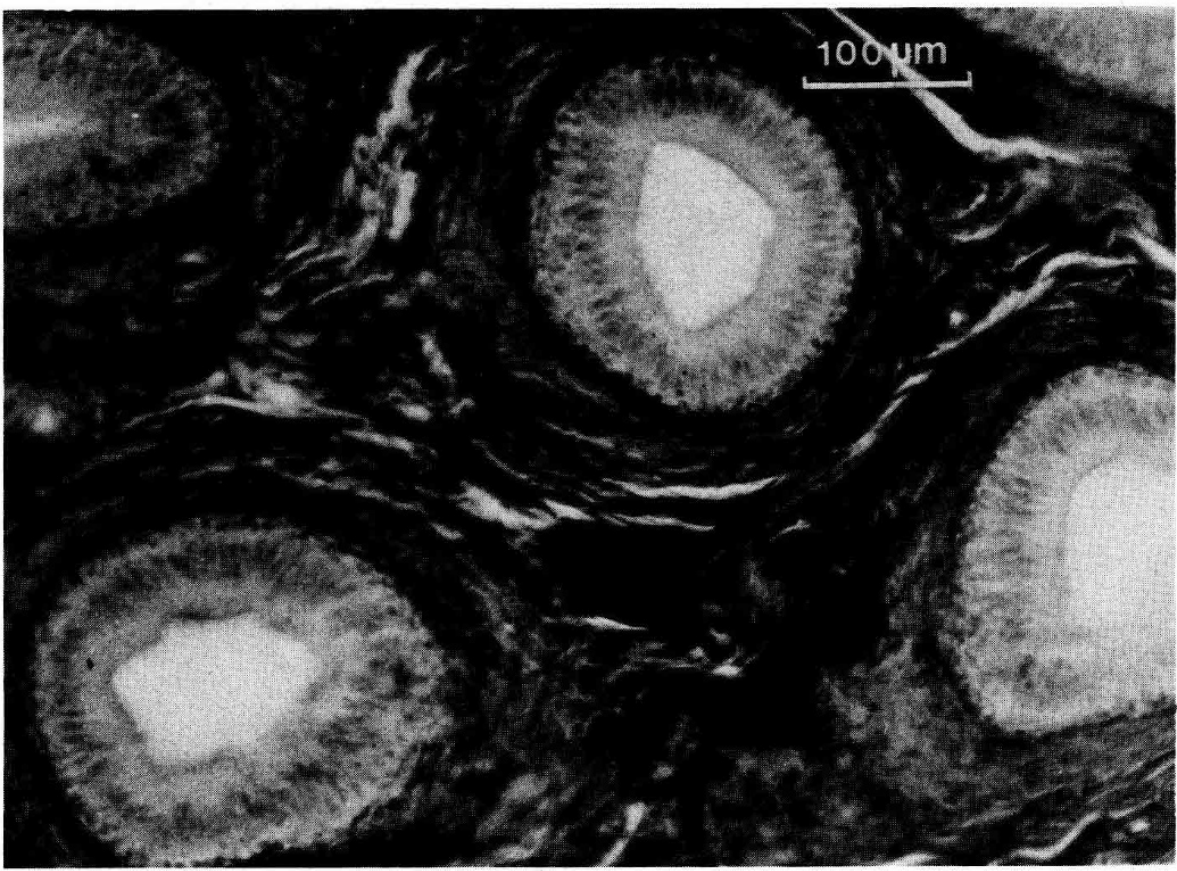

Fig. 4

Canaux épididymaire avec les lumières vides (animal $n^{\circ} 1$ ). Epididymal ducts with empty lumina (animal $n^{\circ} 1$ ).

TABLEAU 1

Nombre et fréquence des cellules mâles et femelles dans le sang, la moelle osseuse et le rein des animaux 1 et 2 .

Number and frequency of male and female cells in blood, bone marrow and kidney of animals 1 and 2.

\begin{tabular}{|c|c|c|c|c|}
\hline $\begin{array}{c}\mathbf{N}^{\circ} \text { de la } \\
\text { brebis }\end{array}$ & Tissu & $\begin{array}{c}\text { Nombre de } \\
\text { cellules femelles }\end{array}$ & $\begin{array}{l}\text { Nombre de } \\
\text { cellules mâles }\end{array}$ & $\begin{array}{l}\text { Pourcentage de } \\
\text { cellules mâles }\end{array}$ \\
\hline 1 & $\begin{array}{l}\text { Sang périphérique } \ldots \ldots \\
\text { Moelle } \ldots \ldots \ldots \ldots \ldots \ldots \ldots \\
\text { Rein } \ldots \ldots \ldots \ldots \ldots \ldots\end{array}$ & $\begin{array}{r}65 \\
50 \\
157\end{array}$ & $\begin{array}{r}54 \\
44 \\
0\end{array}$ & $\begin{array}{r}45 \\
47 \\
0\end{array}$ \\
\hline 2 & $\begin{array}{l}\text { Sang périphérique } \ldots \ldots \\
\text { Moelle } \ldots \ldots \ldots \ldots \ldots \ldots \\
\text { Rein } \ldots \ldots \ldots \ldots \ldots \ldots\end{array}$ & $\begin{array}{r}15 \\
3 \\
153\end{array}$ & $\begin{array}{r}19 \\
48 \\
0\end{array}$ & $\begin{array}{r}56 \\
94 \\
0\end{array}$ \\
\hline
\end{tabular}




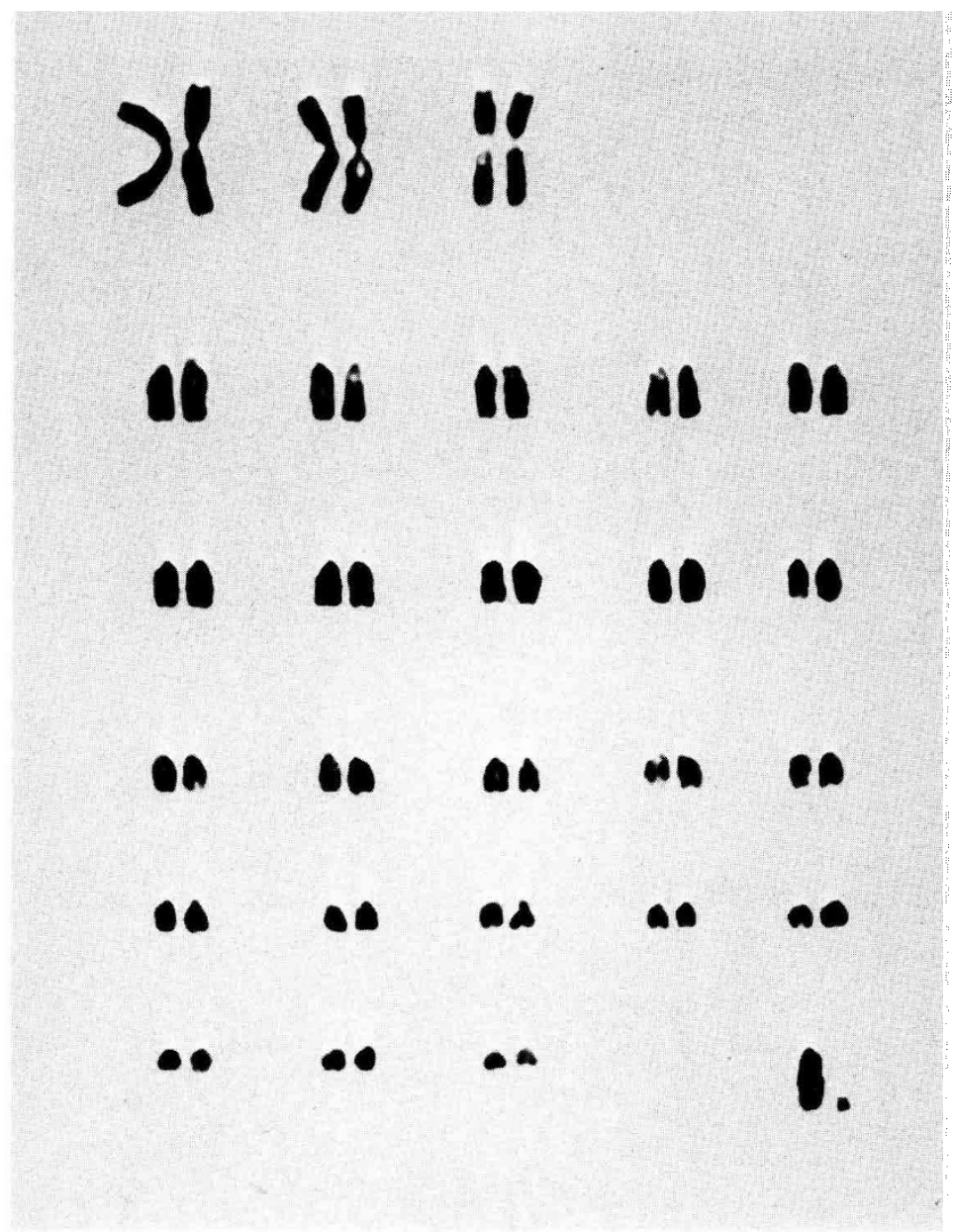

Fig. 5

Caryotype mâle de l'animal $n^{\circ} 2$. Male Karyotype of animal $n^{\circ} 2$.

somes comprenant 3 paires de grands métacentriques et 24 paires d'acrocentriques formant une série de taille décroissante. Les deux chromosomes $\mathbf{X}$ sont les plus grands de la série acrocentrique et possèdent des bras courts très visibles.

Dans les cultures de sang périphérique et de moelle osseuse des métaphases mâles 54,XY et femelles 54,XX ont été observées. Elles ont des caryotypes normaux, semblables à ceux des cellules rénales pour les cellules femelles et comprenant, à la place d'un des chromosomes $\mathrm{X}$, un petit chromosome $\mathrm{Y}$ métacentrique pour les cellules mâles (fig. 5, 6, 7). Les pourcentages de cellules mâles dans le sang et la moelle sont sensiblement du même ordre de grandeur chez l'animal 1 (tabl. 1). Par contre, ils semblent très différents chez la brebis 2 avec 56 p. 100 de cellules mâles dans le sang périphérique et 94 p. 100 dans la moelle (tabl. 1). 


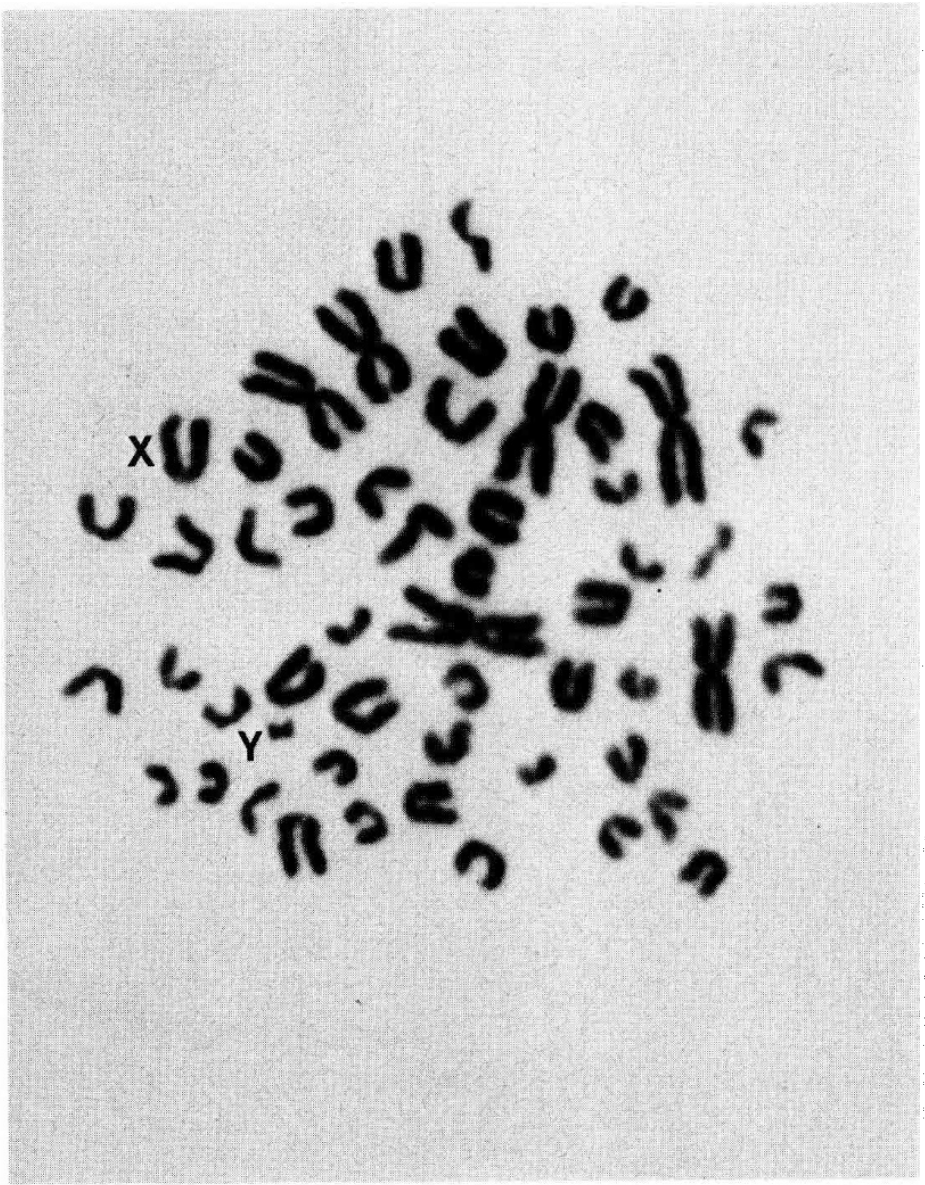

Fig. 6

Cellule mâle lymphocytaire de l'animal $n^{\circ} 1$. Male lymphocyte of animal $n^{0} 1$.

\section{Discussion}

La formation des mixoploïdies XX/XY est causée soit par une succession de non-disjonctions mitotiques des chromosomes sexuels chez le zygote $X Y$, soit par une fertilisation dispermique d'un ovule et de son globule polaire ou de 2 ovules qui fusionnent ensuite, ou enfin par échange de cellules entre co-jumeaux dizygotes hétérosexués pendant le développement utérin (HAMERTON, 1971). La présence d'un chimérisme chromosomique $\mathrm{XX} / \mathrm{XY}$ parmi les lymphocytes du sang et de la moelle et son absence parmi les métaphases observées dans les reins des 2 brebis co-jumelles de mâles, témoignent d'un échange précoce de cellules sanguines souches pendant la gestation (Bibliographie in MARcuM, 1974). Les pourcentages des cellules XY 


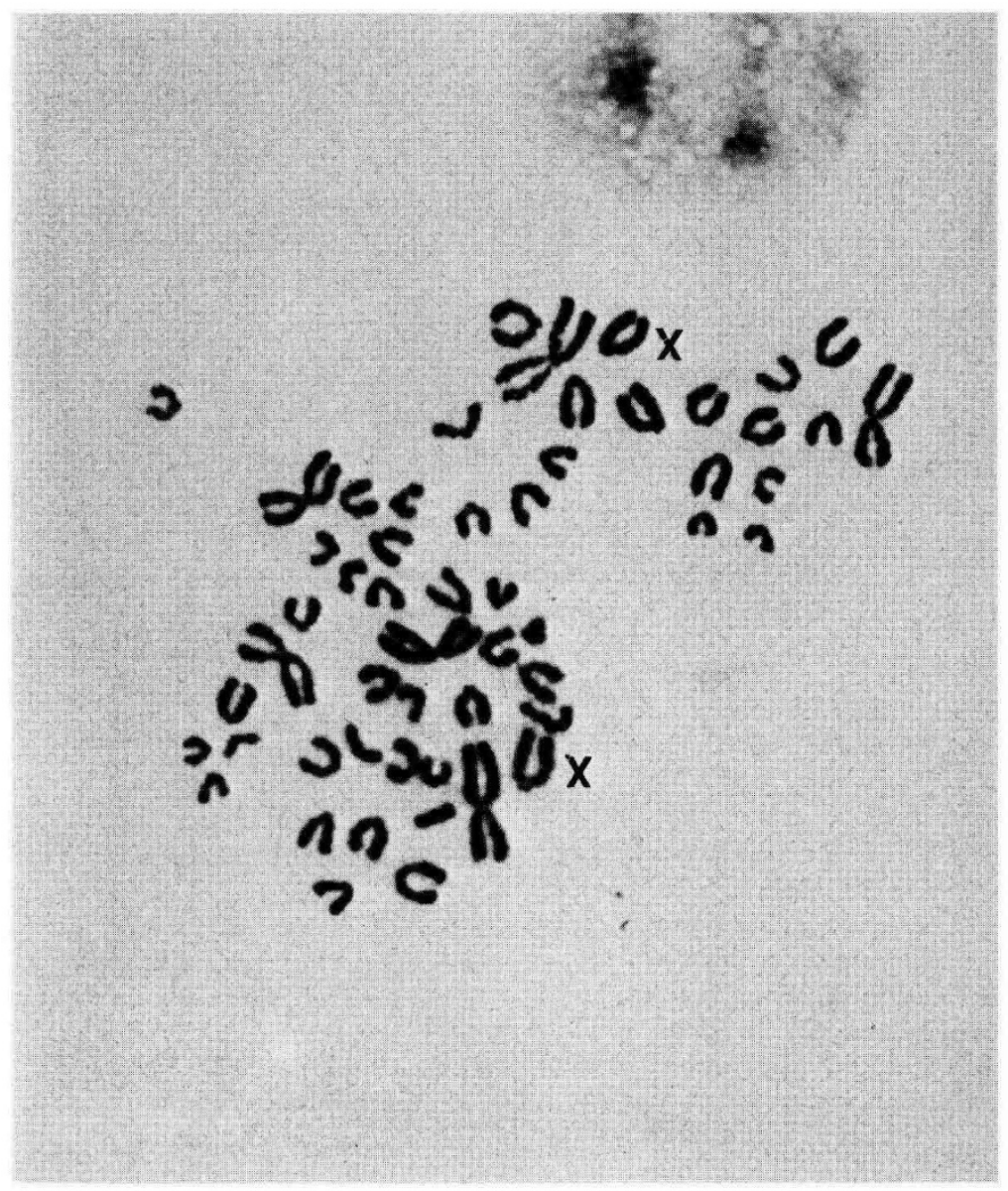

FIG. 7

Cellule femelle rénale de l'animal $n^{0} 1$.

Female kidney cell of animal $n^{\circ} 1$.

dans le sang périphérique des 2 brebis sont très proches, de l'ordre de 50 p. 100 et comme dans la littérature, il n'apparaît pas de relation entre la fréquence de cellules mâles et l'état du tractus génital (tabl. 2).

La différence entre les proportions de cellules mâles dans le sang et la moelle de la brebis 2 est inattendue car les quelques auteurs qui ont effectué ces 2 types de cultures simultanément chez les bovins, ont observé des fréquences très proches (BASRUR \& Kanagawa, 1969). Bien que l'on ne puisse écarter a priori une sélection d'un type cellulaire au cours de la culture in vitro qui précède l'analyse chromosomique, une erreur d'échantillonnage est beaucoup plus probable en raison de la faiblesse de l'effectif (tabl. 1). 


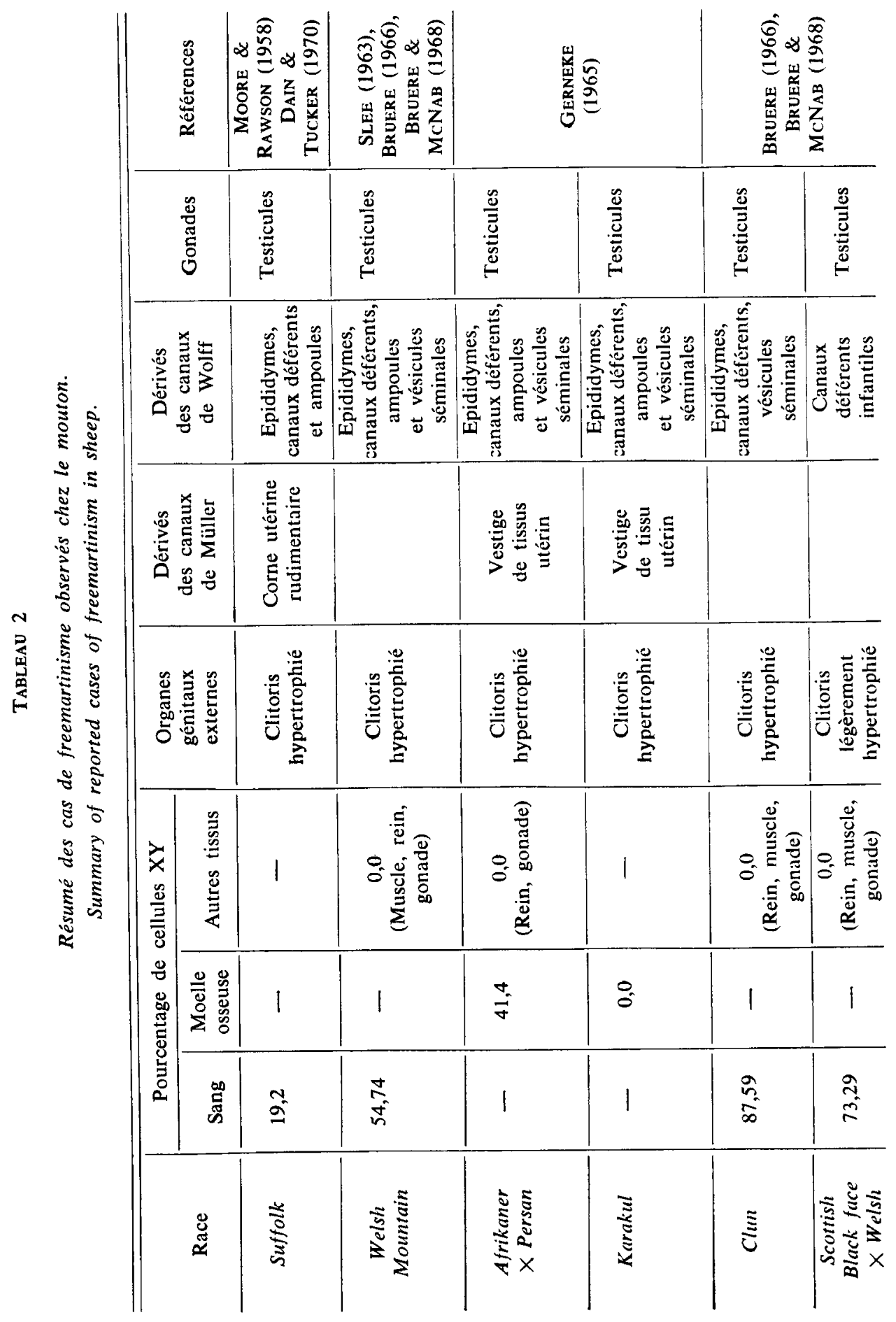




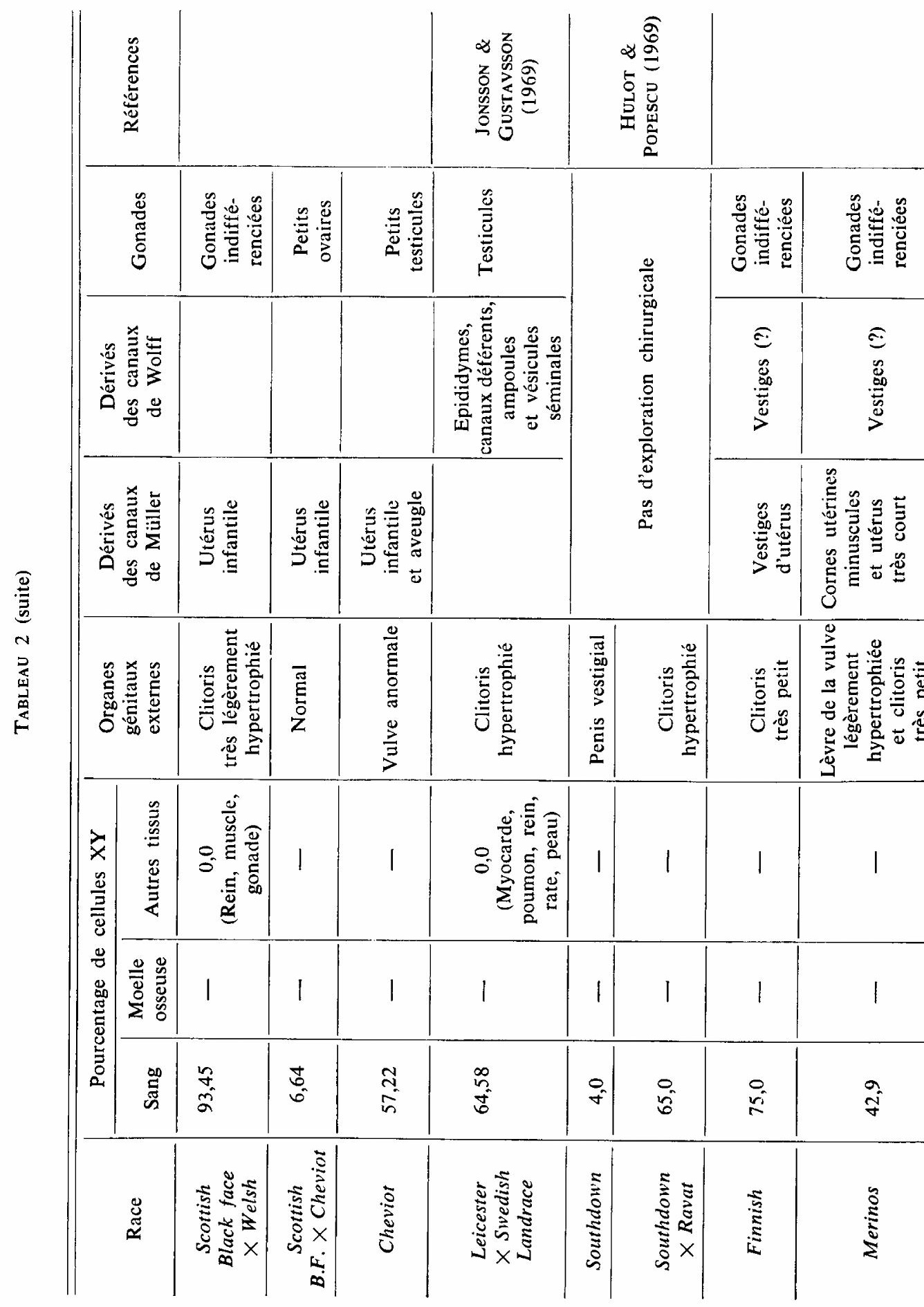




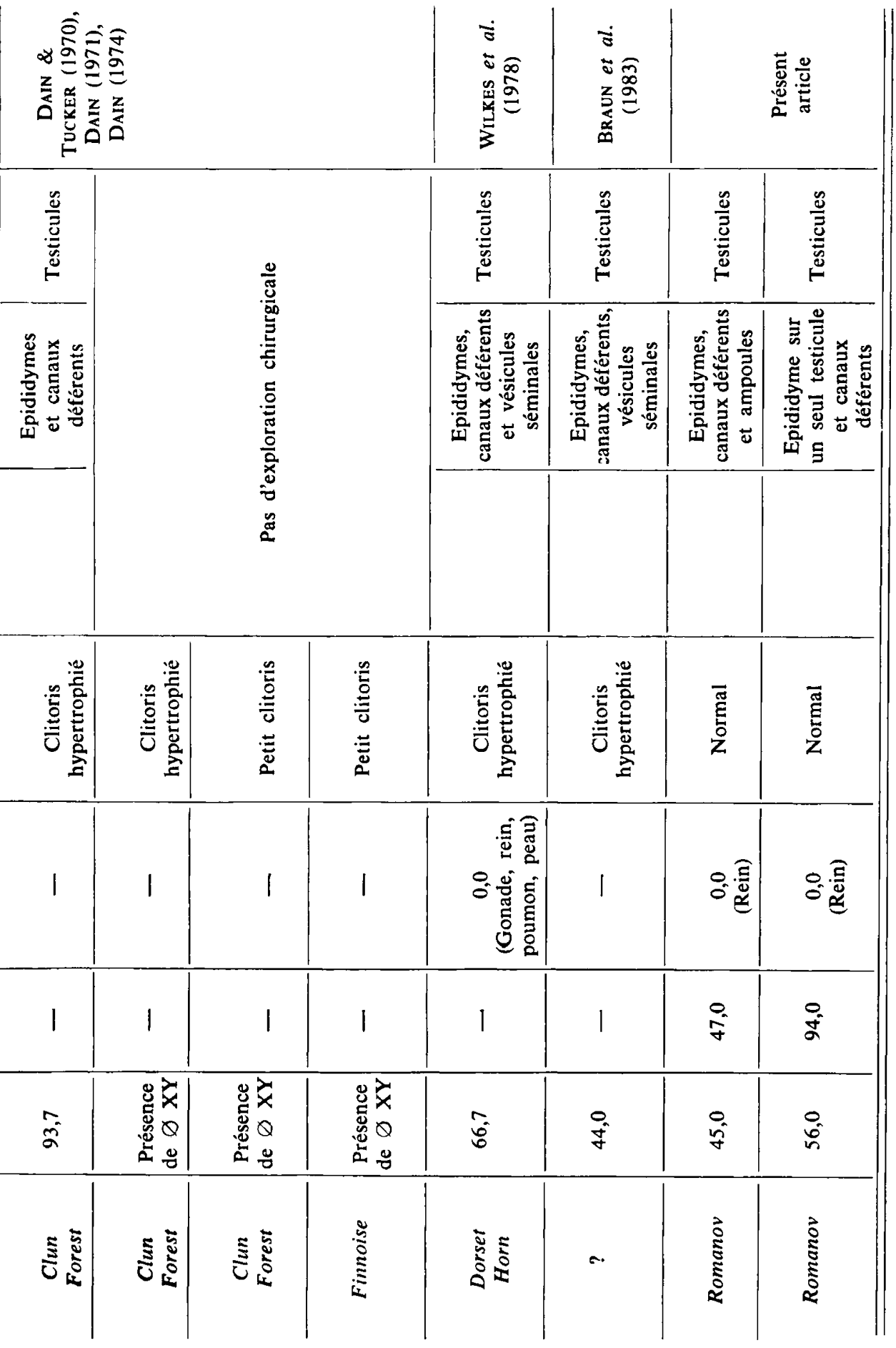


Certains auteurs, comme Bouters \& VandeplassChe (1964), Goodfellow et al. (1965), Kanagawa et al. (1965) et Herschler \& FechHeimer (1967), ont suggéré que la virilisation du tractus génital femelle des bovins est causée par la présence même des cellules mâles. Le rôle et le mécanisme d'action des cellules sanguines $\mathbf{X Y}$ dans la différenciation sexuelle des freemartins sont pourtant complètement inconnus. Cependant cette théorie a rapidement été mise en défaut par les travaux d'une part de Kanagawa et al. (1965), Herzog (1969), Vigier et al. (1972) et Marcum et al. (1972), qui ont confirmé l'absence de corrélation entre l'intensité du freemartinisme et le degré de chimérisme et d'autre part de VIGIER et al. (1976) qui ont démontré que l'interruption chirurgicale des anastomoses vasculaires entre co-jumeaux $\mathrm{XX} / \mathrm{XY}$ avant 45 jours supprime les premières manifestations du freemartinisme caractérisées par l'inhibition du développement de l'ovaire et la régression des canaux de Müller.

La description de l'appareil génital interne des 2 brebis est très proche de celle des freemartins décrits dans la littérature (tabl. 2). Les moutons freemartins semblent se distinguer des bovins par une masculinisation extrême de l'appareil reproducteur interne comprenant une régression complète ou presque complète des canaux de Müller, une stimulation de canaux de Wolff et des gonades ressemblant à des testicules formées de tubes séminifères dépourvus de cellules germinales. Cependant cette fréquence apparemment plus élevée de moutons freemartins très masculinisés, est peut-être due au fait que chez les ovins, les freemartins peu modifiés passent plus facilement inaperçus.

Jost et al. (1972) distinguent 2 phases successives dans le développement prénatal du freemartinisme bovin : tout d'abord «l'effet freemartin» qui se caractérise par l'inhibition du développement du cortex ovarien et la régression des canaux de Müller, puis la phase de masculinisation au cours de laquelle peuvent se former des épididymes, des vésicules séminales et des cordons séminifères dans la gonade. L'hormone antimullérienne, glycoprotéine (PICARD et al., 1978) produite par les cellules de Sertoli (Blanchard \& Josso, 1974; Tran \& Josso, 1982) du co-jumeau mâle est responsable de la régression des canaux de Müller du fœtus freemartin (VIGIER et al., 1984) et pourrait aussi inhiber le développement du cortex ovarien (Jost et al., 1972). Les canaux de Wolff chez le freemartin seraient stimulés par une autre hormone testiculaire (Jost et al., 1972; Vigier et al., 1977) comme la testoterone qui est sécrétée par l'ovaire freemartin dès la première phase (SHORE \& Shemesh, 1981). La masculinisation de l'ovaire a successivement été attribuée à la présence de cellules XY dans la gonade indifférenciée (OHNO et al., 1976) et au passage de l'antigène $\mathrm{H}-\mathrm{Y}$ à travers les anastomoses vasculalires (WACHTEL et al., 1980).

\section{Conclusion}

L'étiologie du syndrome de freemartinisme chez le Mouton est certainement proche de celle des bovins; la masculinisation extrême de l'appareil reproducteur de la plupart des moutons freemartins pouvant être line particularité de l'espèce bien qu'il soit difficile de tirer des conclusions définitives en raison du petit nombre de cas étudiés.

La différence fondamentale entre les 2 espèces est plutôt l'incidence du freemartinisme puisque l'installation d'anastomoses vasculaires entre les fœetus en cas de gestation multiple est presque systématique chez le Bœuf domestique et très rare 
chez le Mouton. Cependant l'accroissement du nombre d'agneaux par portée pourrait entraîner une augmentation de la fréquence de brebis freemartins puisque le pourcentage de portées mixtes est fonction de la taille des portées. Il serait donc intéressant d'effectuer le caryotype de tous les cas de stérilité observés dans ces races prolifiques afin d'estimer l'incidence de cette anomalie.

\section{Reçu le 22 novembre 1984. Accepté le $1^{\text {er }}$ mars 1985.}

\section{Remerciements}

Nous tenons à remercier M. F. Eychenne, Directeur du Domaine de Langlade, pour l'aide qu'il nous a apportée dans la réalisation de ce travail.

\section{Références bibliographiques}

Alexander G., Williams D., 1964. Ovine freemartins. Nature, 201, 1296-1298.

BasRur P.K., Kanagawa H., 1969. Parallelism in chimeric ratios in heterosexual cattle twins. Genetics, 63, 419-425.

Blanchard M.G., Josso N., 1974. Source of the anti-müllerian hormone synthesized by the fetal testes : müllerian-inhibiting activity of fetal bovine Sertoli cells in tissue culture. Pediatr. Res., 8, 968-971.

Bouters R., Vandeplassche M., 1964. The mal sex chromosome as a possible cause of the development of freemartinism in cattle. Vlaam. Diergeneeskd. Tidjschr., 33, 229-241.

Braun U., Forster M., Schams D., 1983. Das Freemartins-Syndrom beim Schaf. Morphologische hormonanalytische und zytogenetische Untersuchungen. Tierärztl. Prax., 11, 293-302.

Bruere A.N., 1966. A study of cytogenetics in the sheep. Ph. D. Thesis, University of Glasgow.

BRUERE A.N., MCNab J., 1968. A cytogenetical investigation of sex intersex sheep shown to be freemartins. Res. Vet. Sci., 9, 170-180.

Dain A., Tucker E.M., 1970. Cytogenetic, anatomical and blood group studies of sheep twin chimaeras. Proc. Roy. Soc. Lond. B., 175, 183-200.

DaIN A., 1971. The incidence of freemartinism in sheep. J. Reprod. Fert., 24, 91-97.

Dain A.., 1974. A study of the proportions of male and female leucocytes in the blood of chimaeric sheep. J. Anat., 118, 53-59.

De Grouchy J., Roubin M., 1965. Une technique d'étude des chromosomes humains à partir d'une culture de fibroblastes. Ann. Génét., 8, 105-106.

GERNEKE W.H., 1965. Chromosomal evidence of the freemartin condition in sheep (Ovis aries). J.S. Afr. Vet. Med. Ass., 36, 99-104.

Goodfellow S., Strong S.J., Stewart J.S.S., 1965. Bovine freemartins and true hermaphroditism. Lancet, 1, 1040.

Hamerton J.L., 1971. Human genetics. 2 Vol. Academic Press, New York.

HanRahan J.P., 1984. Results on selection for increased litter size and ovulation rate in sheep. 2nd World Congress on Sheep and beef Cattle Breeding, Pretoria, 16-19 A pril 1984, South Africa, 483-493. Ed. J.H. HofmeYr, E.H.H. MEYer. South African Stud Book and livestock improvement association.

Herschler M.S., FechHeimer N.S., 1967. The role of sex chromosome chimerism in altering sexual development of mammals. Cytogenetics, 6, 204-212.

HERzoG A., 1969. Are the pathological anatomical findings on the sexual organs of freemartins and the quantative relation of gonadal chimaerism (XX/XY) in blood cells correlated? Zuchthygiene, 4, 156-159. 
Hulot F., Popescu C.P., 1969. Deux cas d'intersexualité chromosomique chez le Mouton (Ovis aries L.) Ann. Génét. Sél. Anim., 1, 9-13.

Johnsson G., GuSTavsson I., 1969. Blood cell chimerism in one of three triplet lambs. J. Hered., 60, 174-179.

Jost A., Vigier B., Prepin J., 1972. Freemartins in cattle : the first steps of sexual organogenesis. J. Reprod. Fert., 29, 349-379.

Kanagawa H., Kawata K., Ishikawa T., Muramoto J., Ono H., 1965. Sex chromosome chimerism $(\mathrm{XX} / \mathrm{XY})$ in heterosexual bovine triplets. Jap. J. Vet. Res., 13, 121-126.

Keller K., TANDLER J., 1916. The behaviour of the chorion in twin pregnancies of cattle. Wien. Tierärztl. Monatsschr., 3, 513-526.

Lillie F.R., 1917. The freemartin; a study of the action of sex hormones in the foetal life of cattle. J. Exp. Zool., 23, 371-452.

Marcum J.B., Lasley J.F., DaY B.N. 1972. Variability of sex chromosome chimerism in cattle from heterosexual multiple births. Cytogenetics, 11, 388-399.

Marcum J.B., 1974. "The freemartin Syndrome». Animal Breeding Abst., 42, 227-242.

MOORE N.W. Rowson L.E.A., 1958. Freemartins in sheep. Nature, 182, 1754-1755.

Ohno S., Trujillo J.M., Stenius C., Christian L.C., Teplitz R.L., 1962. Possible germ cell chimeras among newborn dizygotic twin calves (Bos taurus). Cytogenetics, 1, 258-265.

Ohno S., Christian L., Wachtel S.S., Koo G.C., 1976. Hormone-like role of H-Y antigen in bovine freemartin gonad. Nature 261, 597-599.

OWEN J.B., Brown K., Flint R., 1980. Selection for prolificacy in sheep in relation to meat production characters. 31st animal Meeting, E.A.A.P., Munich, 1-4 September 1980, $G 1-9,6$ pages ronéotypées.

OWEN R.D., 1945. Immunogenetic consequences of vascular anastomoses between bovine twins. Science, 102, 400-401.

PiCard J.Y., Tran D., Josso N., 1980. Une nouvelle glycoprotéine : l'hormone anti-müllérienne. Ann. Endocrinol., 41, 281-290.

Picon R., Picon L., Chaffaux S., Ktorza A., 1978 : Effects of canine fetal testes and testicular tumors on Mullerian ducts. Biol. Reprod., 18, 459-467.

Ricordeau G., Razungles J., Lajous D., 1982. Heritability of ovulation rate and level of embryonic losses in Romanov breed. 2nd World Congress on Genetics applied to Livestock Production. Madrid, 4-8 October 1982, GARSI (éd.), Madrid, Vol. VII, 591-595.

Sheib-Gluntz P., 1984. Caractères généraux et potentialité cytophysiologique du Sertolinome canin. Thèse de doctorat vétérinaire, E.N.V.A., Maisons-Alfort.

Shore L., Shemesh M., 1981. Altered steroidogenesis by the fetal bovine freemartin ovary. J. Reprod. Fert., 63, 309-314.

SLEE J., 1963. Immunological tolerance between litter-mates in sheep. Nature, 200, 654-656.

Stormont C., Weir W.C., LANE L.L., 1953. Erythrocyte mosaicism in a pair of sheep twins. Science, 118, 695-696.

Tran D., Josso N., 1982. Localization of anti-Müllerian hormone in the rough endoplasmic reticulum of the developing bovine Sertoli cell using immunocytochemistry with a monoclonal antibody. Endocrinology, 111, 1562-1567.

Vigier B., Prepin J., Jost A., 1972. Absence de corrélation entre le chimérisme XX/XY dans le foie et les premiers signes du freemartinisme chez le foetus de veau. Cytogenetics, 11, 81-101.

Vigier B., Locatelli A., Prepin J., Du Mesnil du Buisson F., Jost A., 1976. Les premières manifestations du freemartinisme chez le fœtus de veau ne dépendent pas du chimérisme chromosomique XX/XY. C.R. Acad. Sci., 285, 1355-1358.

Vigier B., Prepin J., Perchellet J.P., Jost A., 1977. Le développement de l'effet freemartin chez le fotus de veau. Ann. Méd. Vét., 121, 521-536.

Vigier B., Tran D., Legeai L., Bezard J., Josso N., 1984. Origin of anti-Müllerian hormone in bovine freemartin fetuses. J. Reprod. Fert., 70, 473-479.

Wachtel S.S., Hall J.L., Muller U., Chaganti R.S.K., 1980. Serumborne H-Y antigen in the fetal bovine freemartin. Cell., 21, 917-926.

Wilkes P.R., Munro I.B., Wijeratne W.V.S., 1978. Studies on a sheep freemartin. Vet. Rec., 102, 140-142. 